\title{
THE CULTURAL PREPARATION OF THE TEACHER OF ENGLISH AS A SECOND LANGUAGE
}

\author{
Albert H. Marckwardt \\ The University of Michigan
}

For many years foreign language study, in this country at least, has been justified on the ground that proficiency in the language constitutes a key to the understanding of the culture of a country and the psychology and personality traits of its people. Today we continue to accept this premise, tempered only perhaps by the somewhat more cautious caveat that such cultural insights will be attained only if they occupy a prominent place among the language course objectives and if some way of implementing them can be carefully worked out.

Certainly one of the aims which an agency like USIA or possibly the Peace Corps program hopes to achieve in its English teaching, as well as in its other cultural programs, is an understanding of the United States and of the American people. Similarly, unless students from abroad who come to study in the United States do manage to acquire such a cultural rapprochement from their English courses and their orientation experiences, a large part of the purpose in having them here goes unrealized.

The point that this understanding is by no means an automatic by-product of language study, whether English, Russian, or Swahili, has already been made. It must be planned, must constitute an integral, though not necessarily an overt, part of the curriculum. Such planning requires culturally oriented materials on the one hand, and culturally sophisticated teachers to present them on the other.

This is scarcely the place to discuss culturally oriented materials. Nevertheless, we do depend upon a contrastive linquistic analysis to identify those features of a target language which will require little conscious drill because they are the same in the native language of the learner, as well as those features of the target language which will require concentrated drill to fix them as automatic responses because they differ from patterns of the native language. Just so, it may be reasonably maintained that contrastive cultural analyses are equally important in terms of the aims of language study that have just been stated. 
Our concern here, however, is with the teacher and with the program designed to train or educate him. We grant an important place to linguistics in a curriculum intended to prepare effective teachers because we hope that the individual teacher will be able to control his textbook rather than to have it dominate him. We hope that he may be able to analyze the individual or group difficulties of his students and then to supplement or clarify the text when the occasion arises. In short, we hope to achieve in the well-prepared teacher a high degree of linguistic sophistication and intellectual self-reliance.

The moment that the development of cultural insights and cultural understanding becomes an important course aim, cultural sophistication becomes a requisite for success in teaching. Moreover, just as there are two facets to linguistic sophistication, namely a scientifically sound concept of the structure of both the target and the native language, so are there two corresponding elements which are included in an adequate program of cultural preparation.

The teacher of English as a foreign language must be equipped with a well-rounded knowledge of the culture or cultures represented by his students. The necessity of this is readily apparent if he is to pursue his career in a foreign country, but it is equally necessary, although perhaps less readily attainable, if he practices his profession at home.

How else will he even begin to comprehend the shock that the single pronoun of address in English will cause in his active Japanese students whose cultures as well as whose language is marked by an honorific hierarchy? How else will he understand that a swift, stream-lined progression which is considered a virtue, not only in the English essay or narrative but in nearly all situations involving communication between English-speaking persons will seem hasty and skeletal in a culture such as the Southeast Asian which delights in a somewhat baroque elaboration of detail. The old story about the girl who meant "maybe" when she said "no" and "yes" when she said "maybe" has something instructive in it for us, in reverse at least, for there are cultures in which a flat unmodified negative is never given as a direct reply, except perhaps as an absolute insult. And note that I have dealt here with cultural patterns which have linguistic as well as behavioral implications.

In the course of our work in preparing teachers many of us have discovered that the innocence of the American about foreign cultures is equaled only by his ignorance of his own. How many of us can give a cogent explanation of our tendency toward quantitative statements and evaluations. For our tendency 
toward gilding the commonplace with the aura of the elegant. For our predilection toward overstatement rather than the understatement characteristic of the British. For our firm commitment to local control of public education-something which is always puzzling to foreigners.

Or, to reverse the procedure and go from the historical fact to the modern consequence, what was the impact of the frontier upon the American character and value system? How are the facts of settlement history reflected in our present regional subcultures or, for that matter, our dialects? To what degree did the intellectual temperament of the two outstanding minds of the eighteenth century, Franklin and Jefferson, shape the subsequent development of our science and technology? What were the relative influence of Mary Wollstonecraft and Hannah More upon the position of women in this country? The answers to questions such as these are indispensable to an understanding of ourselves as a people, and without understanding, interpretation is reduced to impotence.

Closely connected with this is another tactical point which should not escape our notice. Though the effectiveness of American linguistically oriented teaching materials has been clearly demonstrated, the teacher who employs them is likely to be regarded as a skillful technician, but somewhat limited. In many countries, language teaching is still chiefly in the control of those whose education has been strongly colored by a belletristic tradition. If the American teacher can talk with certain of his foreign counterparts not merely about the efficacy of pattern practice or the syntactic role of suprasegmentals but about the New England Renaissance, the Gilded Age, The Revolt of the Twenties, and better yet to a German about Novalis and Tieck or to a Mexican about Sor Juana Inés de la Cruz or Don José Joaquín Fernández de Ligardi, and needless to say give evidence of having read them, he will find an attitude far more receptive toward his ideas of proper language pedagogy.

In short, the knowledge and the intellectual approach which I feel to be a helpful complement to the linguistic competence and the methodological virtuousity of the teacher might well be characterized as a happy combination of the sensitivity of the well-read person, the breadth of the cultural historian and the objectivity of the cultural anthropologist-and much of the subject matter appropriate to all three fields.

I am quite aware that what I am proposing as a highly desirable component of the equipment of the teacher of English as a second language will not be accomplished in a summer training course, nor for that matter in a one-year graduate program. 
On the one hand, I am talking about elements in a continuing education which should be the concern, indeed the responsibility of every member of this division of our profession. On the other, I am suggesting that it is high time that we stop thinking only of relatively short-term training and turn our attention to long-term career preparation in which some of the areas of study I have mentioned should form part of the undergraduate experience of those who elect to follow this field and others might well be appropriate to a carefully-devised doctoral program. 